\title{
Microstructure and selected properties of Monel 400 alloy after laser heat treatment and laser boriding using diode laser
}

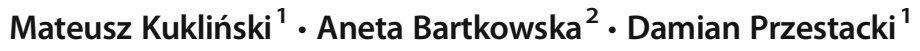

Received: 10 April 2018 / Accepted: 7 June 2018 / Published online: 26 July 2018

(C) The Author(s) 2018

\begin{abstract}
This study concentrates on describing effects of laser heat treatment of Monel 400 and laser alloying its surface with boron. Surfaces without and with initial boron layers of two different thicknesses (100 and $200 \mu \mathrm{m})$ were processed using diode laser. Laser beam power density was constant and equal to $178.3 \mathrm{~kW} / \mathrm{cm}^{2}$. To determine the influence of laser beam scanning velocity on final properties of treated surfaces, laser beam scanning velocity was set on four different values: $5,25,50$, and $75 \mathrm{~m} / \mathrm{min}$. Microstructures of pure Monel 400 and Monel 400 alloyed with $100 \mu \mathrm{m}$ boron content are composed of dendrites. Areas laser alloyed with $200 \mu \mathrm{m}$ boron layer contain mainly nickel borides. Boron addition in Monel 400 surface results in microhardness increase in which the level depends on boron content and the laser beam scanning velocity. Increasing the thickness of initial boron layer and speeding up the laser beam lead to obtain higher microhardness. On the other hand, areas laser alloyed with $200 \mu \mathrm{m}$ boron layer using laser beam scanning velocity equal to $75 \mathrm{~m} / \mathrm{min}$ contain deep cracks which propagate from the surface through the produced layer. Furthermore, it was found that the depths of laser heat-treated areas depend significantly on the boron content. As the result of differences in thermal properties between Monel 400 and boron, depth of re-melted zones in some conditions does not lower with increasing laser beam scanning velocity.
\end{abstract}

Keywords Monel $400 \cdot$ Laser heat treatment $\cdot$ Laser boriding $\cdot$ Diode laser $\cdot$ Microstructure $\cdot$ Microhardness

\section{Introduction}

Monel 400 is a nickel-copper alloy which is mainly known for its high corrosion resistance. It is a one-phase alloy composed of a Ni-Cu solid solution. Monel 400 is resistant against seawater, alkalis, salts, and acids: organic, sulfuric, hydrofluoric, and phosphoric. This alloy is mainly applied in marine engineering and chemical processing as valves, pumps, and tanks. Other applications are electrical and electronic components, crude petroleum stills, and heat exchangers. Monel 400 is also a great material to use at subzero temperatures due to the fact that it does not transition from ductile to brittle even at the

Damian Przestacki

damian.przestacki@put.poznan.pl

1 Faculty of Mechanical Engineering and Management, Institute of Mechanical Technology, Poznan University of Technology, Piotrowo 3, 60-965 Poznan, Poland

2 Faculty of Mechanical Engineering and Management, Institute of Material Science and Engineering, Poznan University of Technology, Jana Pawła II 24, 60-965 Poznan, Poland temperature of liquid hydrogen [1,2]. Products made of this nickel-copper alloy, due to its chemical inertness, are characterized by a long lifetime [3]. However, Monel 400 is characterized by relatively low hardness ranged between 115 and $250 \mathrm{HV}$ (depending on finishing process) and it disqualifies this material from applying where it would be exposed to wear due to erosion, cavitation, or adhesive wear [4].

One of the processes which lead to obtain wear resistant surface on metal substrate is boriding. In this process, boron atoms diffuse into the substrate to form metallic borides of high hardness $[5,6]$. Depending on the substrate material, boriding is also carried out to increase the corrosion resistance $[7,8]$. Current research focuses on boriding of iron alloys [5-9] and, in addition, titanium and its alloys [10], niobium, chromium, tungsten [11], and nickel alloys [12-15]. Boriding of nickel alloys leads to obtaining microstructure consisting of nickel boride mixture with borides of other metals, depending on the type of an alloy, e.g., during boron laser alloying of Inconel or Nimonic alloys, mixtures of nickel and chromium borides are formed. On the other hand, modification of borided surfaces with nickel leads to preventing the brittleness of produced layers $[14,16,17]$. Moreover, it was found that 
addition of copper which is the second main element of Monel 400 , to boron layer, reduces brittleness and enhances wear resistance of the surface $[5,18]$. Borided layers are mostly produced in diffusion processes but in the last two decades of intensive laser techniques progress, there was a much increase in using lasers for obtaining boron-alloyed metal surfaces [14, 16, 17, 19-24] and others [25-36].

Lasers are widely used in metal processing due to their ability to deliver high power focused in a precise spot and quickly heat the material. This feature makes laser a perfect device for obtaining specific properties in metal surface layer due to microstructural modification or changes in chemical composition (if an additional material is supplied to the molten pool). For material processing $\mathrm{CO}_{2}$, $\mathrm{Nd}$ :YAG, excimer and diode lasers are mainly applied $[25,26]$; diode lasers are a great solution due to the fact that they are characterized by high output efficiency. Shorter wavelength of radiation produced with diode lasers results in high absorption in metals and allows to obtain small size of laser spot with a great power density. In addition, diode lasers are characterized by lower maintenance costs and a possibility to deliver a radiation in fiber. These features resulted in raising interest in using diode lasers for metal processing, for example, laser alloying [19-23, 26, 28, 30-33], laser hardening [24, 29, 34], or laser-assisted machining [27, 34-36]. Because of their potential, diode lasers systems are still improved to obtain better beam quality and higher power intensity [29].

In previous surveys of nickel-copper alloys, diode lasers were carried out to investigate the properties of laser-cladded layers in order to additive manufacturing. Obtained results show structures possible to obtain by laser heat treatment of Monel 400. Adak et al. cladded $\mathrm{Cu}-30 \mathrm{Ni}$ alloy using diode laser with different process parameters. Obtained structure is free of cracks and mostly dendritic with a thin layer of cellular type solidification between a cladded layer and the surface [30]. Bhattacharya et al. compared microstructures and mechanical properties of laser-cladded $\mathrm{Cu}-38 \mathrm{Ni}$ alloy using $\mathrm{CO}_{2}$ and diode laser. It was found that layers produced with diode laser are built with grains of larger size distribution and exhibit higher tensile properties. On the other hand, layers manufactured using $\mathrm{CO}_{2}$ laser are relatively hard but the microhardness results distribution is non-uniform as compared to diode laser formed specimens [31].

Some researches were carried out to investigate factors influencing properties of laser-borided layers produced on nickel-copper alloys. In general, enriching $\mathrm{Ni}-\mathrm{Cu}$ alloys with boron results in obtaining microstructure with nickel borides containing small amount of copper, dispersed in a $\mathrm{Ni}-\mathrm{Cu}$ solid solution. Nakata et al. found, using $\mathrm{CO}_{2}$ laser, that hardness of the alloyed layer increases continuously with the increasing the content of nickel due mainly to the formation of hard boron particles. Moreover, the same survey showed that wear resistance of the laser-alloyed layer improved 40 times, irrespective of $\mathrm{Ni}$ content [32]. Zhang et al. formed $\mathrm{NiCrSiB}$ layer on Monel 400 using $\mathrm{CO}_{2}$ laser. Dendritic structure with hardness equal to approximately $850 \mathrm{HV}$ was obtained and its phase composition contains $\mathrm{Ni}-\mathrm{Cu}$ solid solution, chromium carbides, and nickel borides. It was found that erosion loss rate of the modified layer is one order of magnitude lower than of the Monel 400. Moreover, corrosion resistance increases approximately 5.7 times as the result of surface modification [33]. Also, diode laser was used in the previous researches to obtain $\mathrm{NiCrSiB}$ coatings with two different proportions between its components on the steel substrate. In this case, it was found that doubling the boron content with simultaneously increasing amounts of $\mathrm{C}, \mathrm{Si}$, and $\mathrm{Cr}$, leads to reducing the share of dendrites and obtaining structure containing mainly nickel borides in solid solution of nickel [37].

There are two objectives of this article. The first is to investigate the influence of diode laser heat treatment of Monel 400 using various laser beam scanning velocities on its microstructure, roughness, and microhardness. The second is to determine modifications in microstructure and microhardness changes resulting from laser-alloying Monel 400 with two different contents of boron and four different laser beam scanning velocities. Parameters of laser heat treatment were chosen basing on previous research focusing on laser processing of Waspaloy [34]. Additionally, on the basis of laser heattreated area depth measurements, the influence of boron content on heat conduction through processed material is considered.

\section{Research methodology}

\subsection{Material}

Material carried out for this experiment is Monel 400. Its chemical composition, as a mass percentage of each element, is given in Table 1. It is a single-phase alloy and its microstructure is presented in Fig. 1. Dimensions of specimens were $30 \mathrm{~mm} \times 20 \mathrm{~mm} \times 12 \mathrm{~mm}$. Monel 400 was laser heat treated without an additional material and laser borided which means laser alloying with boron, by re-melting the material with boron layers 100 and $200 \mu \mathrm{m}$ thick. Amorphous boron powder was deposited on the surface of Monel 400 after mixing it with sodium water glass.

Table 1 Chemical composition of Monel 400 [wt\%]

\begin{tabular}{lllllll}
\hline $\mathrm{Cu}[\%]$ & $\mathrm{Si}[\%]$ & $\mathrm{Fe}[\%]$ & $\mathrm{Mn}[\%]$ & $\mathrm{C}[\%]$ & $\mathrm{S}[\%]$ & $\mathrm{Ni}[\%]$ \\
\hline 31 & 0.5 & 2.5 & 2.0 & 0.3 & 0.024 & Bal. \\
\hline
\end{tabular}




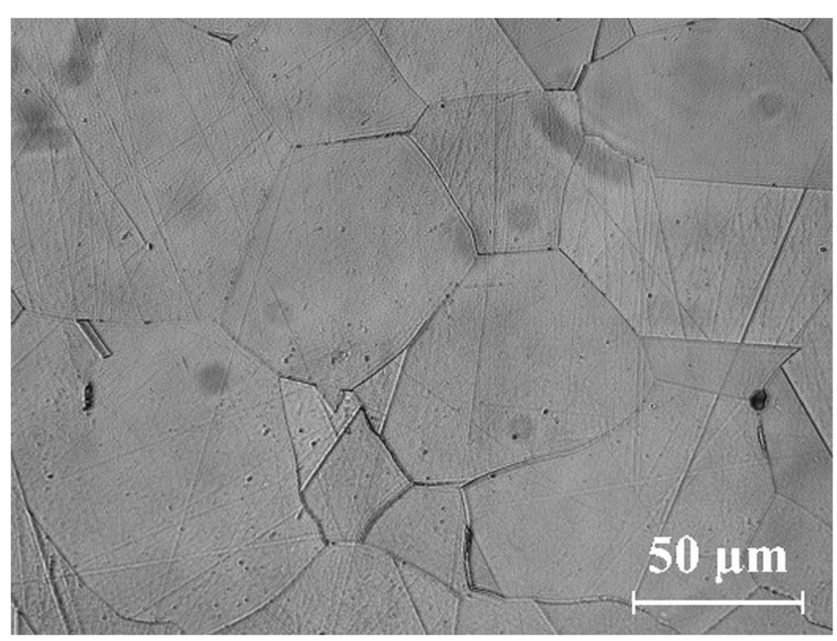

Fig. 1 Monel 400 microstructure

\subsection{Laser heat treatment}

Diode laser carried out for laser heat treatment (LHT) was TRUMPF TruDiode 3006 which reaches $3 \mathrm{~kW}$ of power and is based on single-diode modules. Robot KUKA KR16-2 was integrated with laser to manipulate the location of laser beam. To provide constant laser beam velocity on whole length of laser track, laser beam was started above and turned off behind the specimen. The scheme of the system is presented in Fig. 2.

Laser tracks were produced parallel to longer side of specimen and after each heat treatment laser beam was shifted by $f=0.5 \mathrm{~mm}$. Laser beam power was constant and equal to $P=$ $1400 \mathrm{~W}$ which corresponds to laser beam power density $q=$ $178.3 \mathrm{~kW} / \mathrm{cm}^{2}$. The diameter of laser beam was $d_{1}=1 \mathrm{~mm}$. The parameter which was adjusted during the process was laser beam scanning velocity $\left(v_{1}\right)$. Four values ranging from 5 to $75 \mathrm{~m} / \mathrm{min}$ were set.

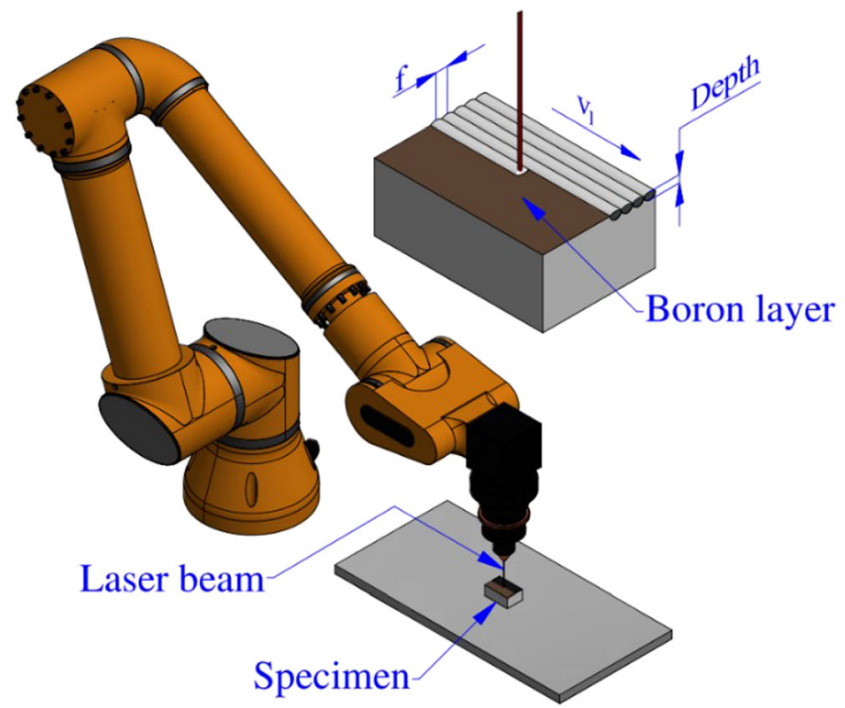

Fig. 2 Scheme of laser heat treatment of Monel 400
Three different types of specimens were laser heat treated with aforementioned parameters. These were as follows: pure Monel 400, Monel 400 with boron layer $100 \mu \mathrm{m}$ thick, and Monel 400 with boron layer of thickness equal to $200 \mu \mathrm{m}$. The summary of process parameters with which each one of three specimen types were treated is given in Table 2 .

\subsection{Sample preparation}

After laser heat treatment, samples were cut across laser tracks to obtain metallographic microsections in a way which reduces any structural changes. Cutting surfaces were grinded with abrasive papers in which grits were ranged from 120 to 2000. Thereafter, they were polished for $20 \mathrm{~min}$ and etched with Marble's reagent for $20 \mathrm{~s}$.

\subsection{Visual investigation}

Initial visual investigation of treated surfaces was carried out using stereomicroscope Stereo Discovery V.20. Pictures of laser tracks' cross-sections were taken with light microscope Opta-Tech of series LAB40 before and after fabrication of microhardness indentations. Dimensions of laser tracks and microhardness indentations were measured using Axio Vision software.

\subsection{Microhardness and roughness testing}

Microhardness indentations were fabricated with Zwick 3212B Vickers tester with constant load equal to $0.9807 \mathrm{~N}$. On each sample, indentations were made on different distances from the surface and five indentations were fabricated in the substrate. Roughness of laser heat-treated surfaces was measured using profilographometer Hommel Tester H500.

\section{Results and discussion}

\subsection{Visual investigation of processed surfaces}

Laser heat-treated surfaces were firstly observed with stereomicroscope for visual investigation. Some taken images were chosen for representation. Figures 3, 4, and 5 present surfaces

Table 2 Laser heat treatment parameters

\begin{tabular}{lllll}
\hline$P[\mathrm{~W}]$ & $q\left[\mathrm{~kW} / \mathrm{cm}^{2}\right]$ & $v_{1}[\mathrm{~m} / \mathrm{min}]$ & $d_{1}[\mathrm{~mm}]$ & $f[\mathrm{~mm}]$ \\
\hline 1400 & 178.3 & 5 & 1 & 0.5 \\
& & 25 & & \\
& & 50 & & \\
\hline
\end{tabular}


Fig. 3 Laser heat-treated surfaces of Monel 400 manufactured with laser beam scanning velocity: a $5 \mathrm{~m} / \mathrm{min}, \mathbf{b} 25 \mathrm{~m} / \mathrm{min}$, c $50 \mathrm{~m} / \mathrm{min}$, and $\mathbf{d} 75 \mathrm{~m} / \mathrm{min}$
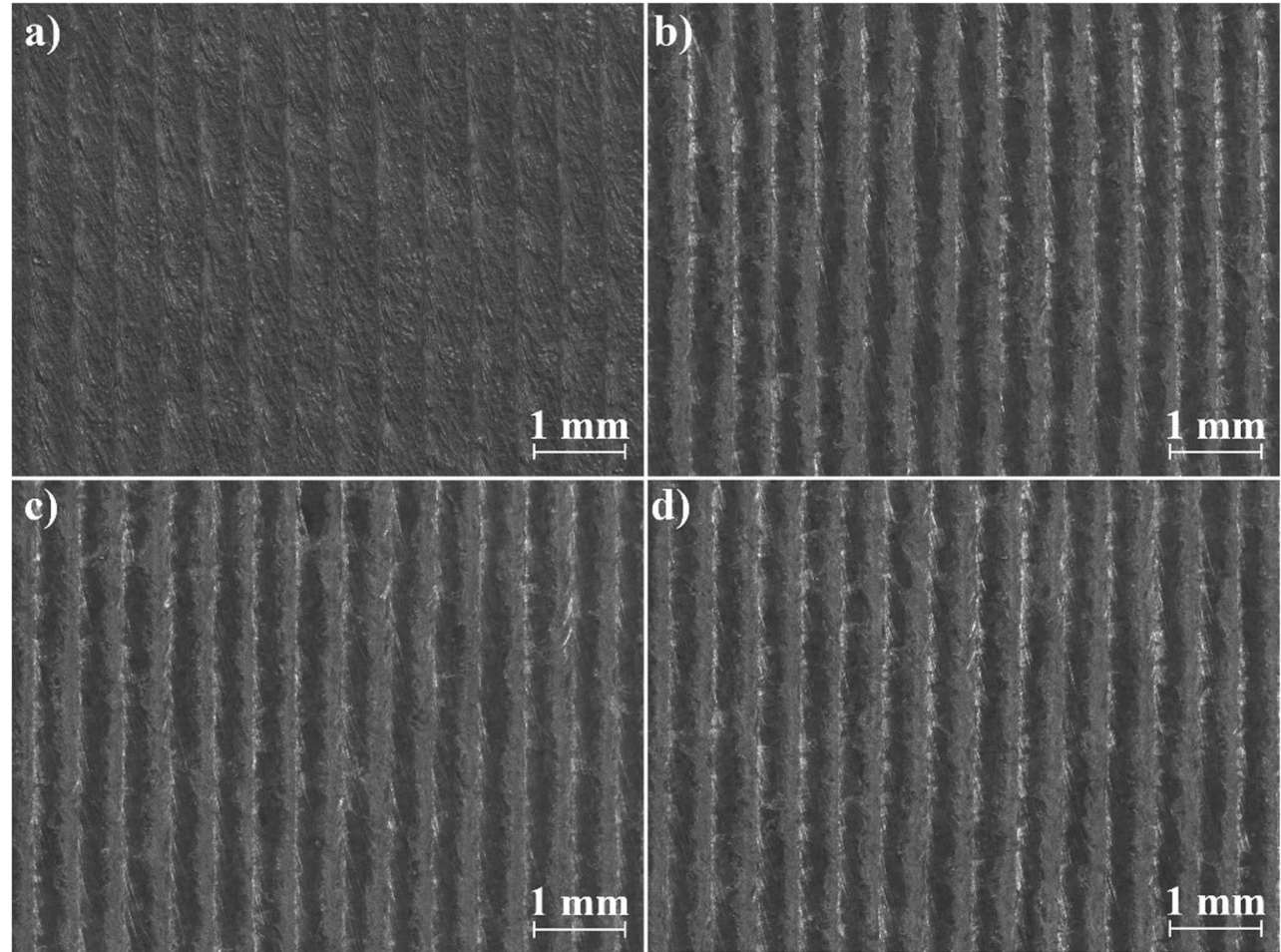

treated with four different laser beam scanning velocities. Laser heat-treated surface of pure Monel 400 is shown in Fig. 3. Surfaces on which boron layers of two different thicknesses were deposited before laser heat treatment are presented in Figs. 4 and 5.

Fig. 4 Surfaces of Monel 400 laser alloyed with $100 \mu \mathrm{m}$ boron layer using laser beam scanning velocity: a $5 \mathrm{~m} / \mathrm{min}$, b $25 \mathrm{~m} / \mathrm{min}$, c $50 \mathrm{~m} / \mathrm{min}$, and $\mathbf{d} 75 \mathrm{~m} / \mathrm{min}$
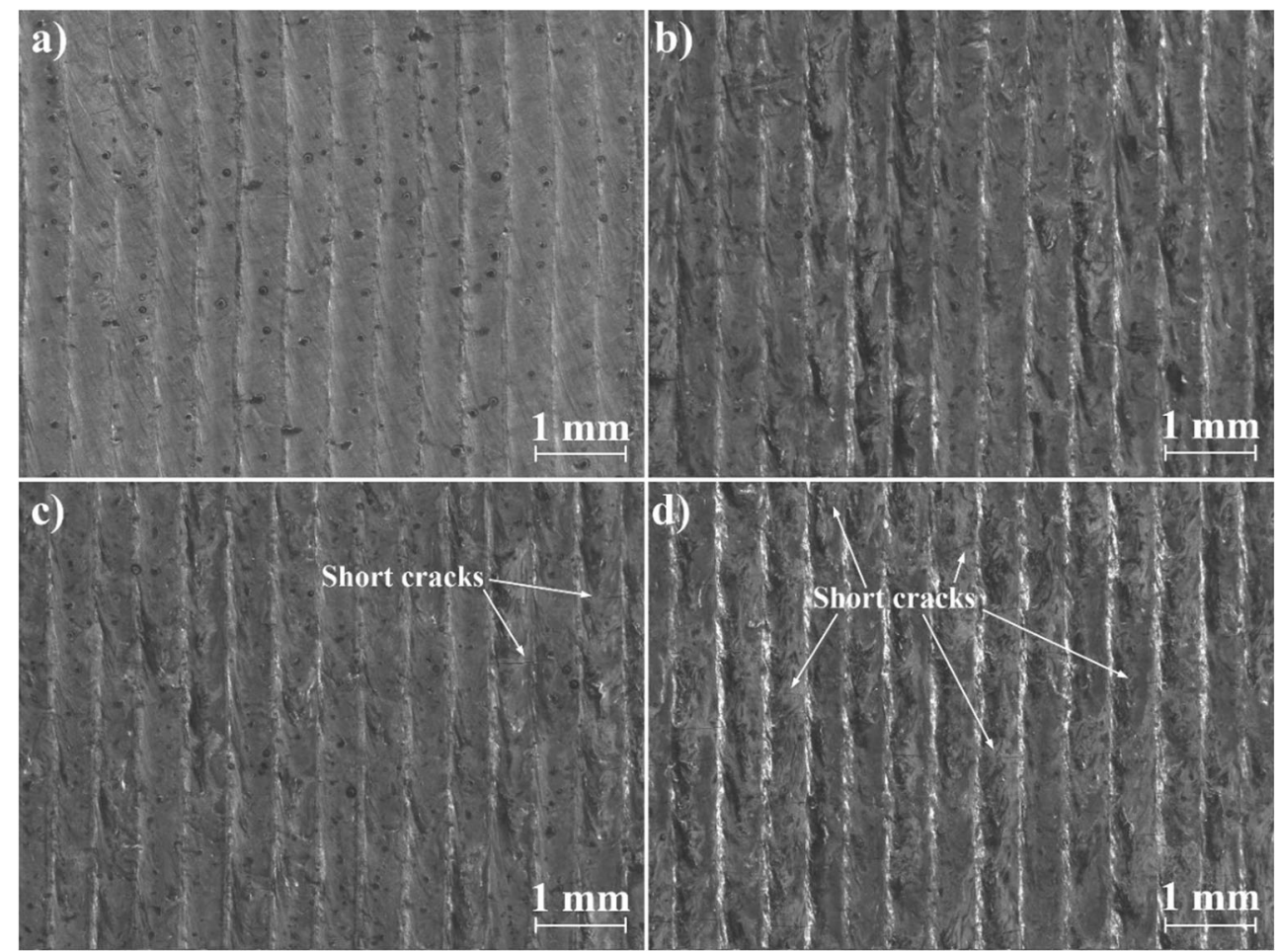
Fig. 5 Surfaces of Monel 400 laser alloyed with $200 \mu \mathrm{m}$ boron layer using laser beam scanning velocity: a $5 \mathrm{~m} / \mathrm{min}$, b $25 \mathrm{~m} / \mathrm{min}$, c $50 \mathrm{~m} / \mathrm{min}$, and $\mathbf{d} 75 \mathrm{~m} / \mathrm{min}$
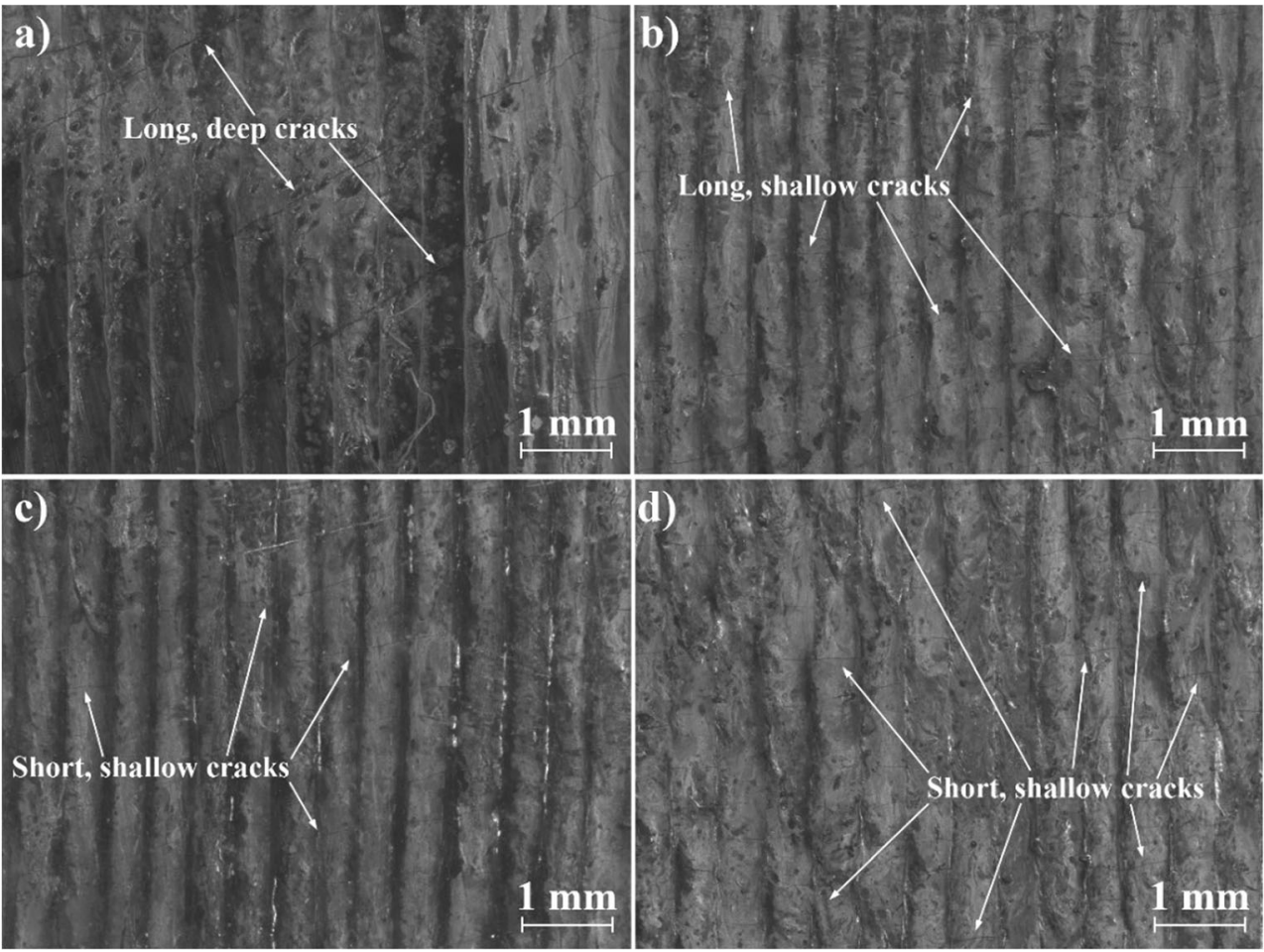

tracks. Furthermore, it was observed that the roughness of treated surface also changes as a result of adjustment laser beam scanning velocity from 5 to $25 \mathrm{~m} / \mathrm{min}$ and it probably remains constant with further speeding up the laser beam.

Surfaces which were laser alloyed with boron seem more irregular and rough than these shown in Fig. 3. These irregularities are the result of fluctuations in thickness of boron layer deposited before laser heat treatment. It is worth noting that boundaries between laser tracks are in approximately same distance from each other. Moreover, it was observed that surfaces laser alloyed with boron contain cracks of different sizes and concentration depending on layer thickness and laser beam scanning velocity. The vast majority of cracks are perpendicular to laser tracks. Shallow and short cracks, no longer than two laser tracks' widths, were spotted on surfaces with $100 \mu \mathrm{m}$ boron layers deposited before the laser heat treatment with a laser beam scanning velocity more than or equal to $25 \mathrm{~m} / \mathrm{min}$. Concentration of these cracks increases with increasing the scanning speed. Surfaces laser alloyed with $200 \mu \mathrm{m}$ initial boron layers contain two types of cracks: longer and shorter. Longer cracks pass across more than ten laser tracks and were spotted on surfaces treated with 5 and $25 \mathrm{~m} / \mathrm{min}$. However, these occurring on surface treated with scanning speed equal to $5 \mathrm{~m} / \mathrm{min}$ are visibly the deepest of all cracks spotted during the investigation. Shorter cracks occur on surfaces treated with higher laser beam scanning velocities and pass across less than five laser tracks but are located more densely. Moreover, due to the high concentration of cracks on surface laser alloyed with $200 \mu \mathrm{m}$ initial boron layer using laser beam scanning velocity equal to $75 \mathrm{~m} / \mathrm{min}$, cracks parallel to laser tracks were detected. These are branches which connect densely located cracks which are perpendicular to laser tracks.

\subsection{Surface roughness}

Laser heat-treated surfaces were examined in terms of roughness. Roughness was measured perpendicularly to laser tracks, across eight of them for each sample. Results obtained as roughness parameters $S_{\mathrm{a}}$ and $S_{\mathrm{z}}$ are summarized and presented in Figs. 6 and 7. $S_{\text {a }}$ parameter is a value of average roughness deviation and $S_{\mathrm{z}}$ is a ten highest point surface irregularity height. Specimens chosen for representation were pure Monel 400 and Monel 400 with addition of boron layer $200 \mu \mathrm{m}$ thick treated with laser beam scanning velocities equal to 5,25 , and $75 \mathrm{~m} / \mathrm{min}$. Besides obtaining these parameters, roughness tests were applied to get three-dimensional models of processed surfaces. These are shown in Figs. 8 and 9 for specimens processed with laser beam scanning velocities 5 and $50 \mathrm{~m} / \mathrm{min}$. Values given near three-dimensional profiles are maximal peak heights measured on an adequate specimen. Additionally, peak height distributions are given.

Comparing values of roughness parameters obtained on pure Monel 400 specimen laser heat treated with three different laser beam scanning velocities, it is seen that the roughness lowered with the increasing scanning speed. Addition of initial boron layer $200 \mu \mathrm{m}$ thick leads to heterogeneous changes in surface quality. Depending on which parameter is considered, laser-alloyed surface seems to be more rough or more 


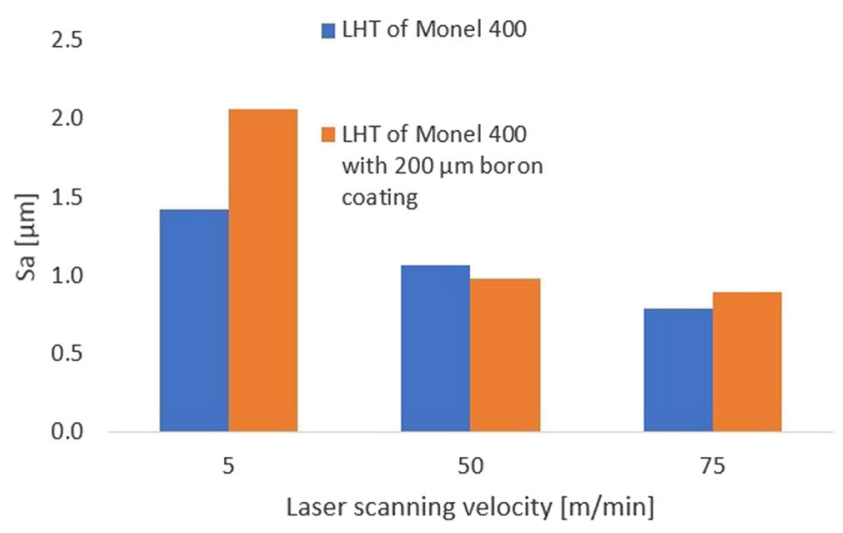

Fig. $6 S_{\text {a }}$ parameters of surfaces processed with three different laser beam scanning velocities

smooth than of pure Monel 400. On the other hand, maximal peak height values which are seen in Figs. 8 and 9 are higher on specimens with initial boron layer put before the laser heat treatment process. Moreover, maximal peaks are higher on specimens processed with a laser beam scanning velocity equal to $5 \mathrm{~m} / \mathrm{min}$ than on those treated with $50 \mathrm{~m} / \mathrm{min}$. Considering graphs presenting peak height distributions, it can be seen that for both laser beam scanning velocities, boron addition results in obtaining surfaces on which the majority of irregularities are higher than average. These phenomena lead to a conclusion that surface roughness become lower with increasing the laser beam scanning velocity and surfaces laser alloyed with boron are more rough than these produced on pure Monel 400. The ambiguity of roughness parameter values of laser-alloyed surfaces is most probably the result of rapid mixing of boron coating with substrate due to the interaction with the laser beam.

\subsection{Microstructure and depth of laser tracks}

Microstructures of laser heat-treated surfaces are presented in Figs. 10-12. In each figure, surfaces treated with four different

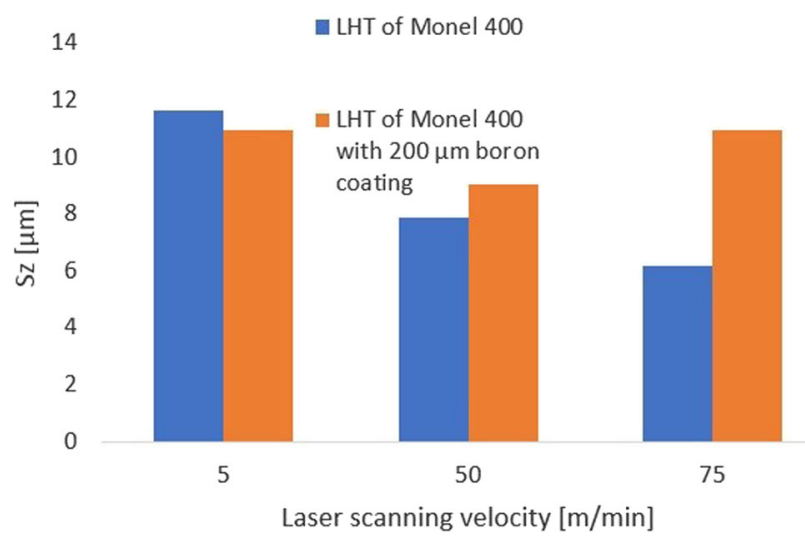

Fig. $7 S_{\mathrm{z}}$ parameters of surfaces processed with three different laser beam scanning velocities laser beam scanning velocities are shown. Figure 10 presents microstructure of laser heat-treated Monel 400 and microstructures obtained by laser-alloying Monel 400 with two different amounts of boron are shown in Figs. 11 and 12. Moreover, results of laser-melted zone thickness measurement were summarized and are shown in Fig. 13.

Figure 10a-d presents microstructures of pure Monel 400 surface layer after laser processing. Significant influence of laser heat treatment on material's microstructure can be seen in specimens processed with both low (Fig. 10a) and higher (Fig. 10b-d) laser beam scanning velocities. As the result of laser modification of Monel 400, in produced melted areas with $\mathrm{Ni}-\mathrm{Cu}$ solid solution structure, a grain orientation arrangement is seen very clearly. Obtained microstructure contains column crystals and dendrites and their growth directions depend on phenomena occurring in a pool of the melted alloy. Numerous turbulences of liquid metal which took place during the laser heat treatment made an impact on the final microstructure. As the result of perpendicular grinding and differences in orientations of crystallization fronts, grains on cross-sections are seen as lengthy or as equiaxed. This is especially seen in Fig. 10a where the melted area is relatively deep. Furthermore, it can be seen that increasing the laser beam scanning velocity results in fragmentation of surface layer microstructure. It was concluded by comparing the sizes of lengthy and equiaxed grains in Fig. 10a-d.

Figures 11 and 12 present microstructures of Monel 400 which were obtained as the result of laser alloying with boron layers of different thickness deposited before the process. Microstructures obtained by laser alloying with $100 \mu \mathrm{m}$ boron layer using different laser beam scanning velocities are presented in Fig. 11a-d. Figure 12a-d presents microstructures of Monel 400 laser alloyed with initial boron layer $200 \mu \mathrm{m}$ thick.

As the result of turbulences during laser alloying of Monel 400 with $100 \mu \mathrm{m}$ boron layer, melted areas microstructures are of clearly visible heterogeneities in chemical composition. It is particularly seen in microstructure obtained due to laser processing with laser beam scanning velocity equal to $75 \mathrm{~m} /$ min which is presented in Fig. 11d. On the basis of phase diagrams and previous research, it may be assumed that boron-nickel eutectic phase exists in obtained structures. Moreover, microstructures of melted areas probably contain nickel borides and $\mathrm{Ni}-\mathrm{Cu}$ solid solution [31].

An increase in the boron content to $200 \mu \mathrm{m}$ thick of initial layer which was subjected to laser radiation leads to obtaining deeper melted zone. Microstructure of these specimens contains mostly bright areas which most probably are formed by nickel borides. It is worth noting that dendritic structure is observed on boundaries between melted areas and the substrate. In described specimens, structural changes resulting from quick heat dissipation and existence of borides are particularly noticeable. Laser-alloyed areas contain pores and 


\section{a)}

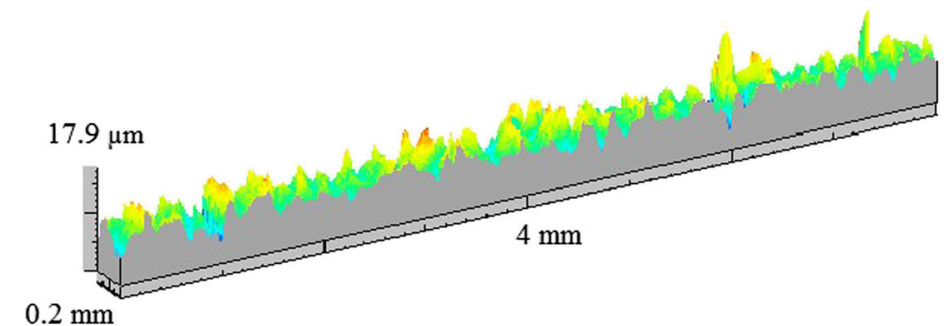

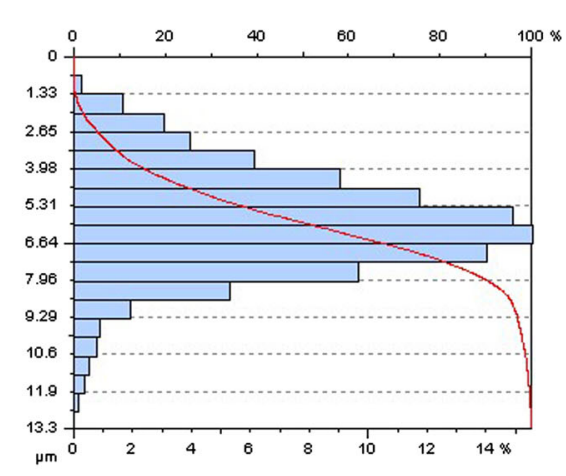

b)
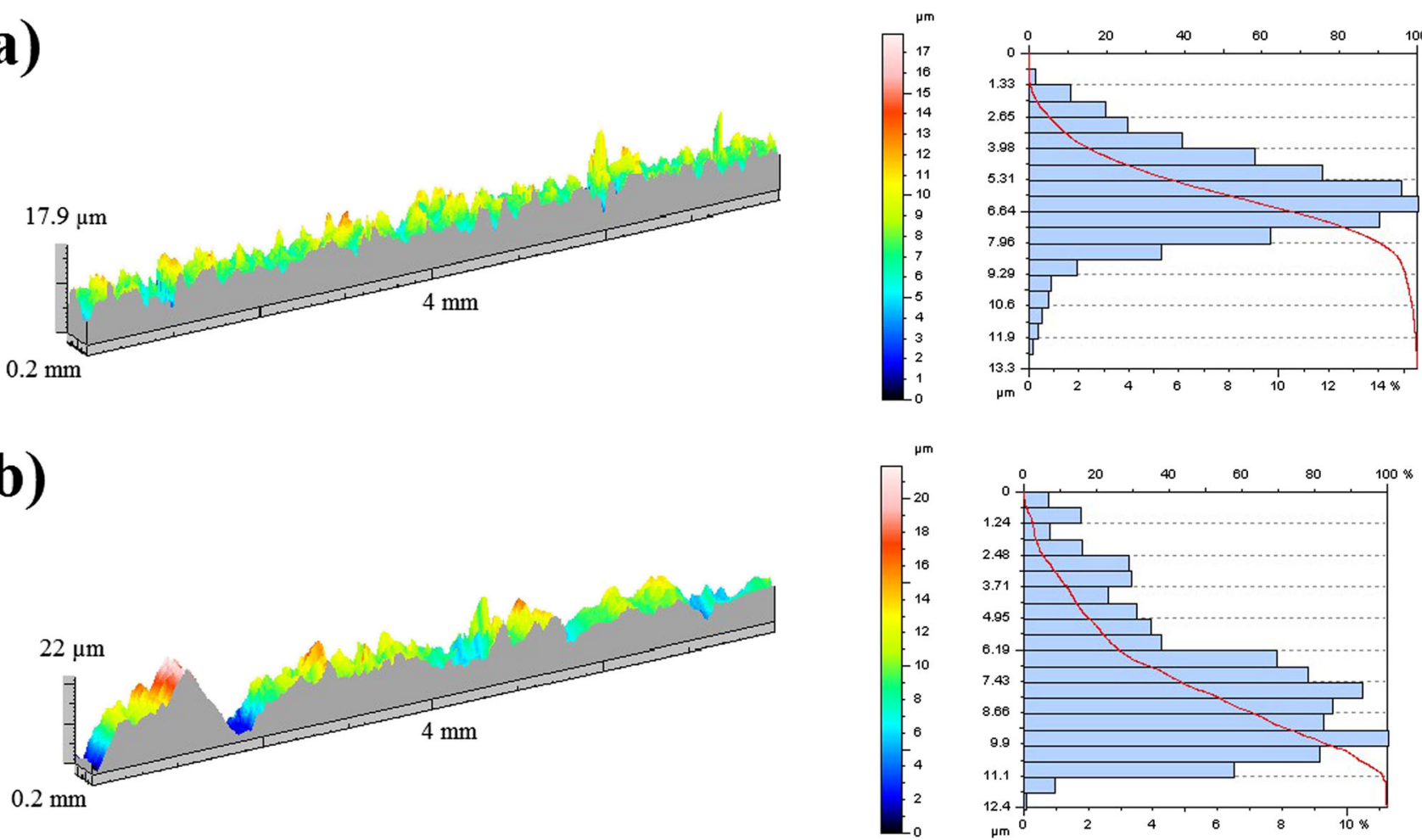

Fig. 8 Three-dimensional roughness profiles of surfaces laser heat treated with scanning velocity $5 \mathrm{~m} / \mathrm{min}$. a pure Monel 400 and b Monel 400 with $200 \mu \mathrm{m}$ initial boron layer

cracks. In specimen laser processed with low laser beam scanning velocity $(5 \mathrm{~m} / \mathrm{min})$, pores are scattered in the whole

volume of melted area, especially in its lower part. Moreover, pores occurring closer to the substrate are visibly

a)
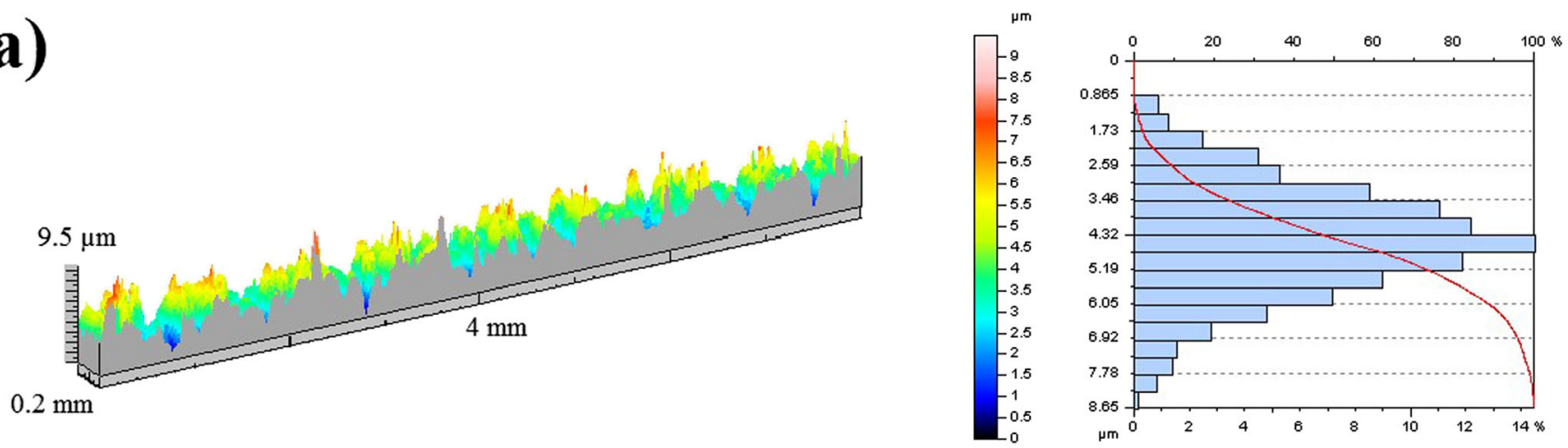

b)
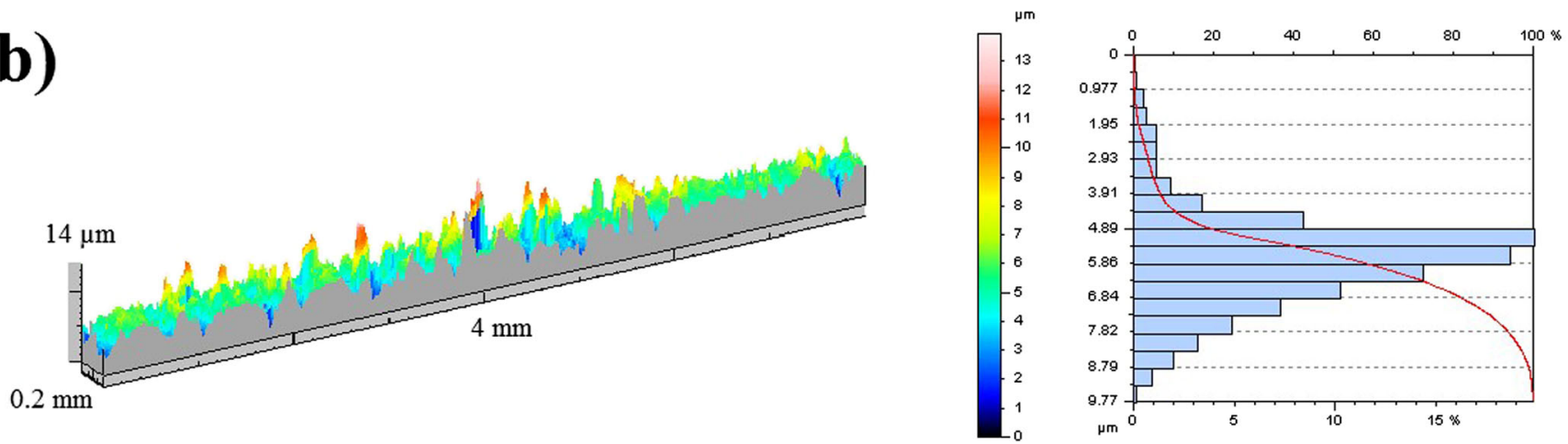

Fig. 9 Three-dimensional roughness profiles of surfaces laser heat treated with scanning velocity $50 \mathrm{~m} / \mathrm{min}$. a pure Monel 400 and b Monel 400 with $200 \mu \mathrm{m}$ initial boron layer 
Fig. 10 Surface of Monel 400 laser heat treated with laser beam scanning velocity: a $5 \mathrm{~m} / \mathrm{min}$, b $25 \mathrm{~m} / \mathrm{min}$, c $50 \mathrm{~m} / \mathrm{min}$, and $\mathbf{d}$ $75 \mathrm{~m} / \mathrm{min}$

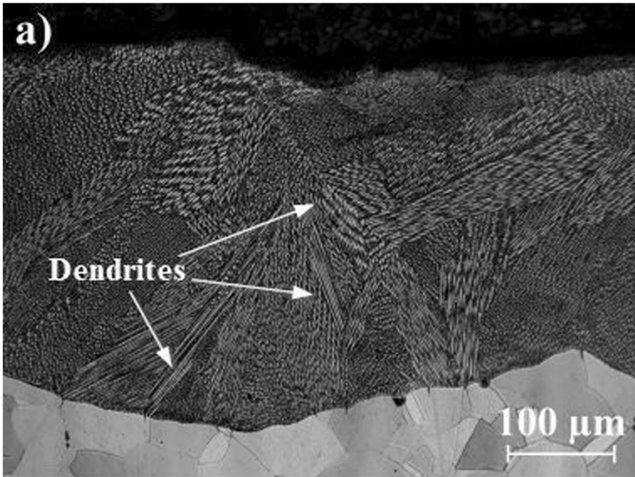

b)
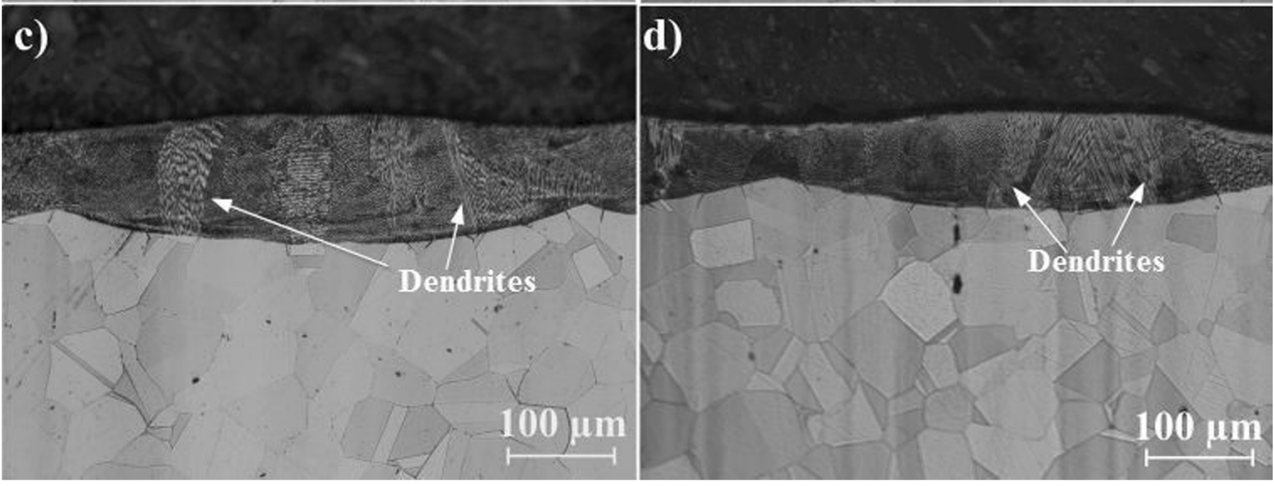

larger. On the other hand, as aforementioned, laser-alloying Monel 400 with boron using the highest considered laser beam scanning velocity $(75 \mathrm{~m} / \mathrm{min})$ results in the formation of cracks parallel to the laser tracks which are seen in Fig. 12d, propagating from the surface to the substrate.
During microstructural investigation, measurements of remelted areas depths were carried out. For each specimen, ten measurements were taken. Summary of average values calculated using obtained results are presented in Fig. 13. The depth of re-melted zone manufactured on Monel 400 alloy using low
Fig. 11 Surface of Monel 400 laser alloyed with $100 \mu \mathrm{m}$ boron layer with laser beam scanning velocity: a $5 \mathrm{~m} / \mathrm{min}$, b $25 \mathrm{~m} / \mathrm{min}$, c $50 \mathrm{~m} / \mathrm{min}$, and $\mathbf{d} 75 \mathrm{~m} / \mathrm{min}$
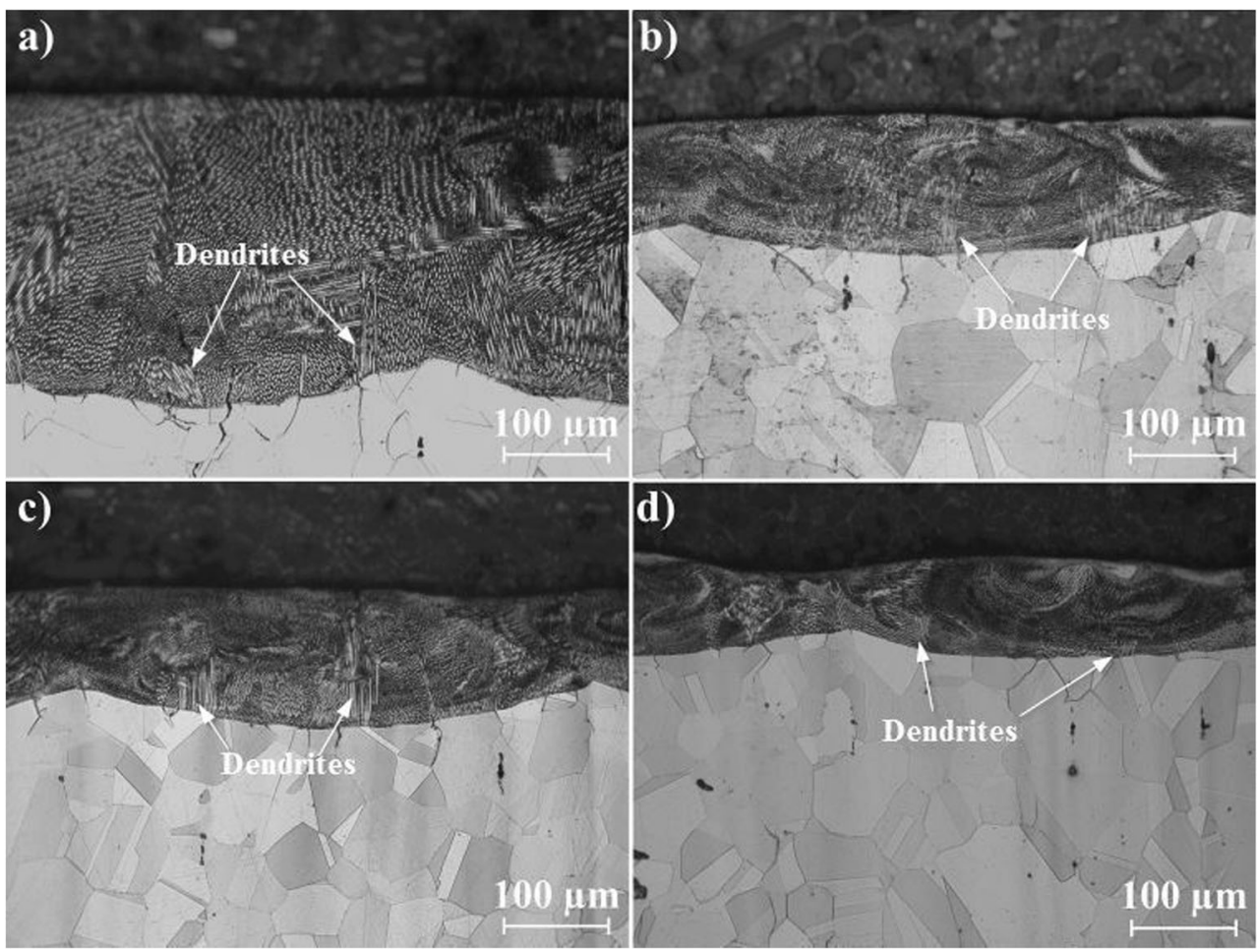
Fig. 12 Surface of Monel 400 laser alloyed with $200 \mu \mathrm{m}$ boron layer with laser beam scanning velocity: a $5 \mathrm{~m} / \mathrm{min}$, b $25 \mathrm{~m} / \mathrm{min}$, c $50 \mathrm{~m} / \mathrm{min}$, and $\mathbf{d} 75 \mathrm{~m} / \mathrm{min}$
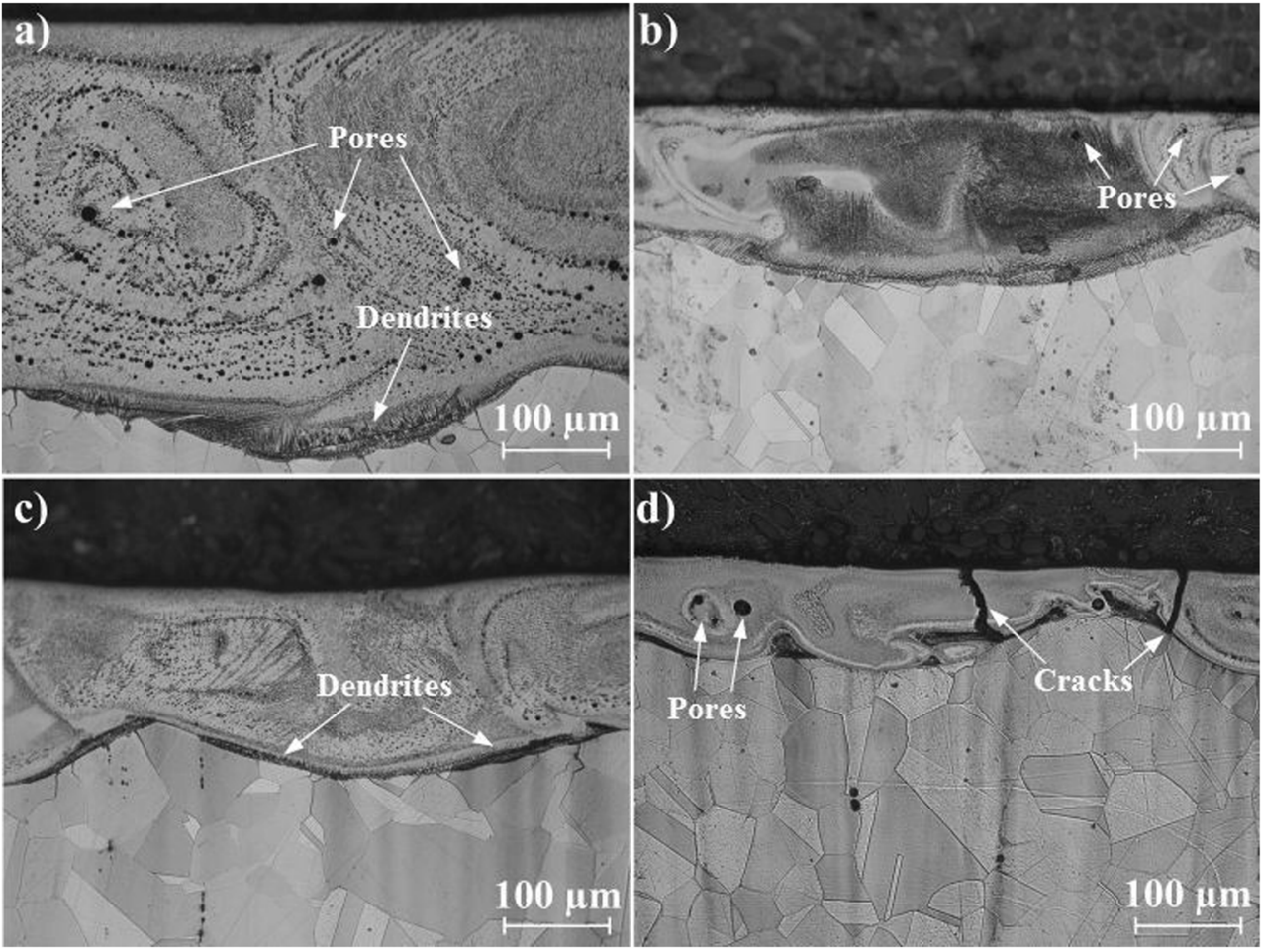

laser beam scanning velocity $(5 \mathrm{~m} / \mathrm{min}$ ) is equal to $362 \mu \mathrm{m}$. Addition of $100 \mu \mathrm{m}$ boron layer on laser-processed surface leads to decreasing the depth of re-melting to $300 \mu \mathrm{m}$. However, doubling the content of boron on the surface before the process results in obtaining re-melted zone $414 \mu \mathrm{m}$ deep.

If the laser heat treatment process is carried out using higher laser beam scanning velocities, ranging from 25 to $75 \mathrm{~m} / \mathrm{min}$, depths of areas with modified structure oscillate between 90 and $180 \mu \mathrm{m}$, depending on the boron content and laser beam scanning velocity. The depth of re-melted zone produced on pure Monel 400 with $25 \mathrm{~m} / \mathrm{min}$ is $94 \mu \mathrm{m}$. The value increases to $134 \mu \mathrm{m}$ due to the addition of initial boron layer of thickness equal to $100 \mu \mathrm{m}$. The trend of increasing the depth of laser modified structure is continuing with raising the content of boron and the re-melted area produced with $200 \mu \mathrm{m}$ boron layer using $25 \mathrm{~m} / \mathrm{min}$ is $177 \mu \mathrm{m}$ deep. Proportions between depths of areas processed with laser beam scanning velocity equal to $50 \mathrm{~m} / \mathrm{min}$ and different boron contents are similar;

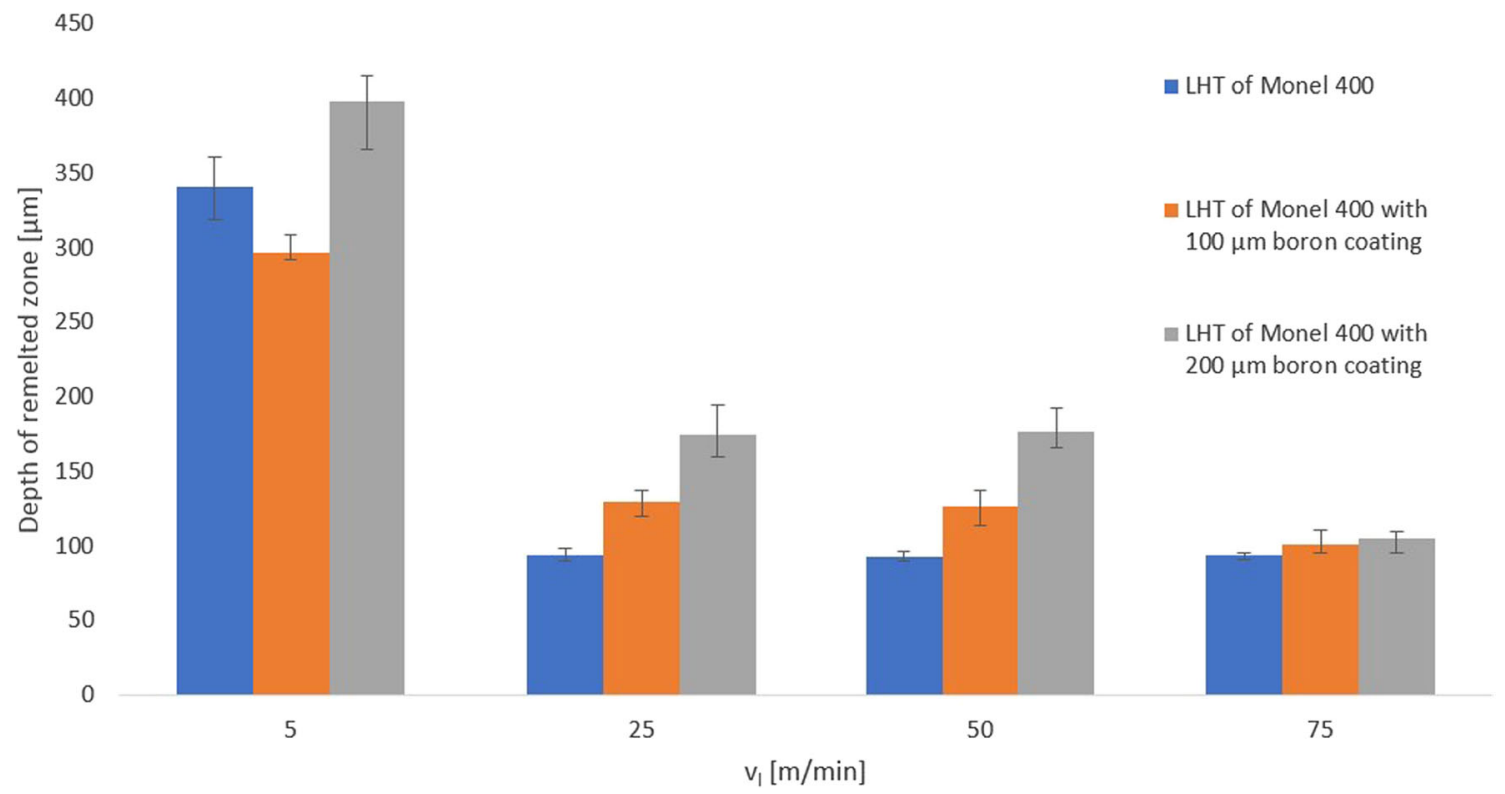

Fig. 13 Average values of laser heat-treated areas thickness 
however, slightly more shallow laser tracks were obtained. The depth of laser modified surface layer on pure Monel 400 is equal to $93 \mu \mathrm{m}$. The addition of boron initial layer $100 \mu \mathrm{m}$ thick results in re-melting $129 \mu \mathrm{m}$ of material, and if the initial layer is $200 \mu \mathrm{m}$ thick, it is $175 \mu \mathrm{m}$. The lowest increase in depth of re-melted areas due to the addition of boron is observed in specimens processed with the highest considered laser beam scanning velocity $(75 \mathrm{~m} / \mathrm{min})$. In this case, while the depth of laser-modified structure on pure Monel 400 is similar to previous values and equal to $93 \mu \mathrm{m}$, surface layers which were laser alloyed with boron are ranged between 100 and $105 \mu \mathrm{m}$. The average depth of area laser alloyed with initial boron layer $100 \mu \mathrm{m}$ thick is $102 \mu \mathrm{m}$ and with boron layer of thickness $200 \mu \mathrm{m}$ is $105 \mu \mathrm{m}$.

It is worth noting that the size of re-melted area on pure Monel 400 with low laser beam scanning velocity is approximately four times larger than of tracks produced with higher scanning speeds. The reason is that exposure time of laser beam during the process carried out with $5 \mathrm{~m} / \mathrm{min}$ is long enough to conduct so much heat through material that it is melting not only as the result of interaction with laser radiation but also with the molten pool. Taking into account that areas re-melted with higher laser beam scanning velocities are almost equal in size, it is considered that scanning speed at which disappears the process of melting temperature conduction through the material is between 5 and $25 \mathrm{~m} / \mathrm{min}$.

Considering values of thermal conductivity and heat capacity of Monel 400 and boron which are presented in Table 3, it is understandable that re-melted areas become deeper with increasing the boron content. However, the depth of area laser alloyed with initial boron layer $100 \mu \mathrm{m}$ thick using laser beam scanning velocity equal to $5 \mathrm{~m} / \mathrm{min}$ is lower than expected. In this case, it is considered that low concentration of borides in large molten volume led to decreasing the value of total thermal conductivity. This effect does not occur in specimen laser alloyed with initial boron layer with a thickness of $200 \mu \mathrm{m}$ because high concentration of borides leads to conduct the heat mainly through them. Therefore, due to the fact that heat conductivity of borides themselves is higher than of Monel 400 (Table 3), re-melted area is deeper with a high initial content of boron. Moreover, this effect is not detected in specimens treated with higher laser beam scanning velocities because of the smaller volume melted during the process which is the reason of higher boride concentration.

Another exception from the aforementioned phenomenon of obtaining deeper laser tracks with increasing the boron content was detected between specimen laser alloyed with scanning velocity equal to $75 \mathrm{~m} / \mathrm{min}$. It can be seen in Fig. 10 that the depth of area re-melted with boron layer $200 \mu \mathrm{m}$ thick is only insignificantly deeper than of area with an initial boron layer with a thickness of $100 \mu \mathrm{m}$. Due to the high heat capacity of boron (given in Table 3), it is considered that with so high laser beam scanning velocity, exposure time
Table 3 Thermal properties of selected substances in room temperature

\begin{tabular}{lll}
\hline Substance & $\begin{array}{l}\text { Thermal conductivity } \\
{[\mathrm{W} /(\mathrm{m} \mathrm{K})]}\end{array}$ & $\begin{array}{l}\text { Heat capacity } \\
{[\mathrm{J} /(\mathrm{g} \mathrm{K})]}\end{array}$ \\
\hline Copper & $400[38]$ & $0.384[38]$ \\
Nickel & $91[39]$ & $0.445[39]$ \\
Monel 400 & $22[4]$ & $0.427[4]$ \\
Boron & $27[40]$ & $1.030[40]$ \\
$\mathrm{Ni}_{3} \mathrm{~B}$ & $42[41]$ & $0.400[42]$ \\
$\mathrm{NiB}$ & $22[41]$ & $0.481[42]$ \\
\hline
\end{tabular}

of laser radiation is too low to heat the surface layer to the stage at which melting of the material occurs as the result of interaction with the molten pool.

\subsection{Microhardness}

During microhardness testing, indentations were fabricated in different distances from the surface. Besides indentations in laser-processed zones, for each specimen, five indentations were fabricated in the substrate. For detailed analysis of microhardness changes, specimens produced with two different scanning beam laser velocities were chosen. Relations between microhardness and distance from the surface for specimen laser heat treated with laser beam scanning velocities 5 and $50 \mathrm{~m} / \mathrm{min}$ are presented in Figs. 14 and 15. Dashed lines of adequate colors indicate average depths of laser tracks.

Results of microhardness measurement on specimens processed with laser beam scanning velocity equal to $5 \mathrm{~m} / \mathrm{min}$ and three different contents of boron are presented in Fig. 14. Microhardness of pure Monel 400 re-melted area is ranged between 150 and $200 \mathrm{HV} 0.1$. Comparing these results with these measured in the substrate (minimal 147 HV0.1 and maximal $206 \mathrm{HV} 0.1$ ) proves that laser heat treatment of Monel 400 with scanning speed equal to $5 \mathrm{~m} / \mathrm{min}$ does not affect its microhardness despite stated microstructural changes. Microhardness changes however if initial boron layer is put on the Monel 400 surface before the process. Laser alloying of Monel 400 with boron layer $100 \mu \mathrm{m}$ thick increases microhardness of re-melted area to values ranged between 300 and $340 \mathrm{HV} 0.1$. This increase in microhardness is related with the existence of a small amount of hard borides in surface layer microstructure. Significant change in surface layer microhardness occurs if the boron content is doubled to a thickness of $200 \mu \mathrm{m}$ of the initial layer. In this case, results of microhardness measurement are ranged between 820 and 910 HV0.1. Laser alloying of Monel 400 with $200 \mu \mathrm{m}$ boron layer using laser beam scanning velocity equal to $5 \mathrm{~m} / \mathrm{min}$ increases its microhardness almost five times. This leads to a conclusion that surface layer manufactured this way contains large quantity of nickel borides which hardness was identified in previous research to be over $1000 \mathrm{HV}$ [13]. 


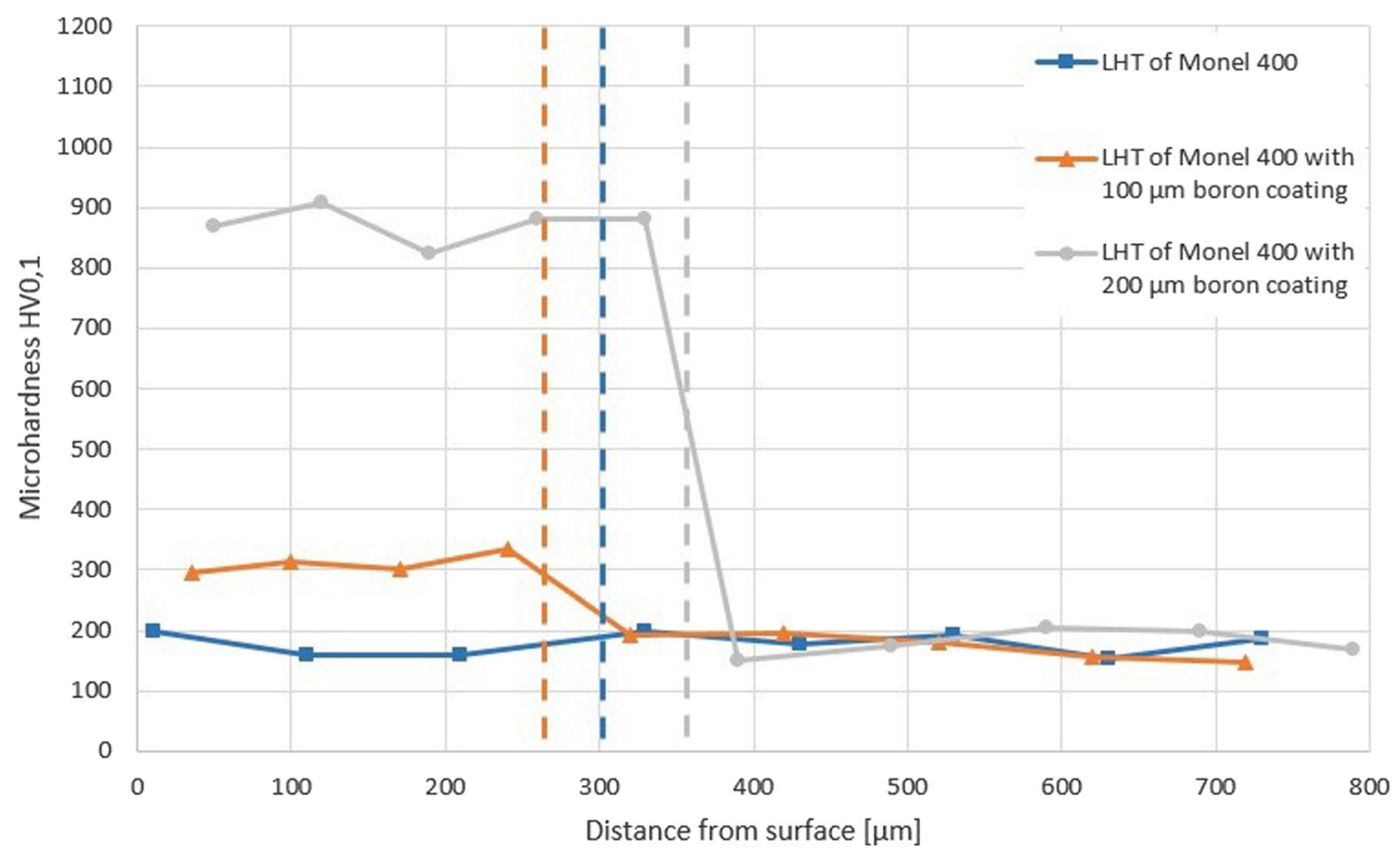

Fig. 14 Microhardness of specimen laser heat treated with scanning speed $5 \mathrm{~m} / \mathrm{min}$ in different distances from surfaces

Microhardness profiles of re-melted zones manufactured using laser beam scanning velocity $50 \mathrm{~m} / \mathrm{min}$ are presented in Fig. 15. In this case, microhardness of pure Monel 400 after laser treatment is slightly higher than before the process. Results of microhardness measurement in re-melted zone of Monel 400 are between 194 HV0.1, closest to the substrate, and 209 HV0.1 near the surface. As predicted, microhardness of the material increased significantly after laser heat treatment with boron initially deposited on the surface. Laser alloying of Monel 400 with boron layer $100 \mu \mathrm{m}$ thick lead to obtaining structure of microhardness ranged between 380 and $500 \mathrm{HV} 0.1$, whereby the lowest value was measured close to the substrate. Doubling the initial boron content to $200 \mu \mathrm{m}$ thickness results in achieving microhardness of the surface layer ranging from 850 to $1100 \mathrm{HV} 0.1$. It is worth noting that these values decrease continuously along with increasing the distance from the surface. Comparing microhardness

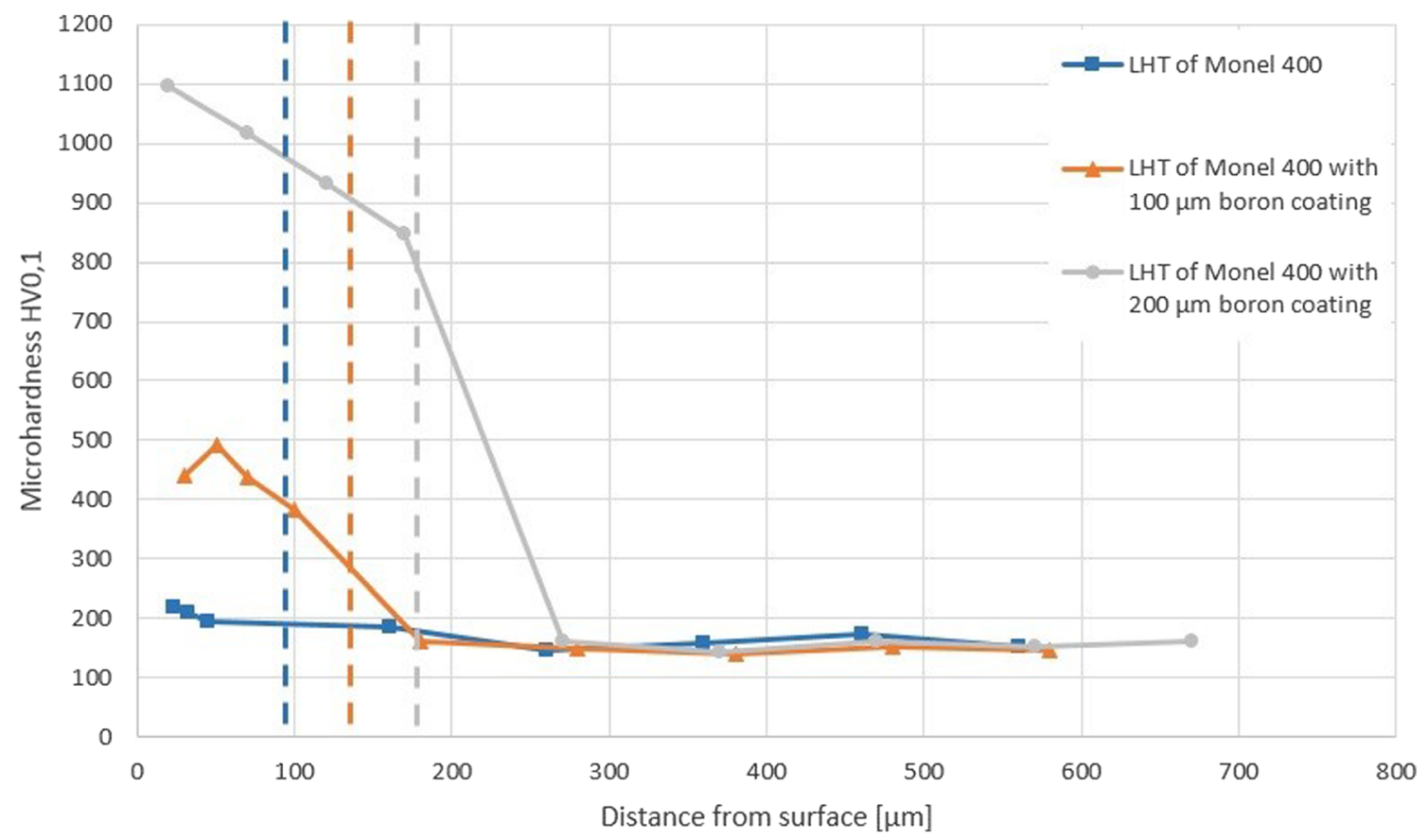

Fig. 15 Microhardness of specimen laser heat treated with scanning speed $50 \mathrm{~m} / \mathrm{min}$ in different distances from surfaces 
measured in re-melted area and of the substrate, it was concluded that laser alloying of Monel 400 with $200 \mu \mathrm{m}$ boron layer using laser beam scanning velocity equal to $50 \mathrm{~m} / \mathrm{min}$ increases the microhardness over five times near the surface and over four times close to the substrate.

It was observed that increasing laser beam scanning velocity for laser alloying of Monel 400 with boron leads to obtaining harder surface layer. The highest measured value of microhardness in area re-melted with initial boron layer $100 \mu \mathrm{m}$ thick using laser beam scanning velocity equal to $5 \mathrm{~m} / \mathrm{min}$ is $335 \mathrm{HV} 0.1$ and using $50 \mathrm{~m} / \mathrm{min}$ is $493 \mathrm{HV} 01$. The difference in microhardness obtained with two different laser beam scanning velocities is $47 \%$. The maximal values measured in areas alloyed with $200 \mu \mathrm{m}$ boron layer using laser beam scanning velocities 5 and $50 \mathrm{~m} / \mathrm{min}$ are respectively equal to $907 \mathrm{HV} 0.1$ and 1097 HV0.1, meaning an increase of $21 \%$. This phenomenon is a result of similar boron content in smaller re-melted volumes which causes higher concentration of borides.

Values of microhardness in specimens manufactured with $5 \mathrm{~m} / \mathrm{min}$ are almost uniform through the entire depth of laser tracks, contrary to microhardness profiles of surface layers processed with $50 \mathrm{~m} / \mathrm{min}$. These are characterized by a decrease in microhardness in the direction of the substrate. This phenomenon is caused by heterogeneous mixing of substrate and boron in the molten pool.

\section{Conclusions}

After an investigation of changes in microstructure and selected properties in surface layer of Monel 400 after laser heat treatment and boriding using diode laser, the following conclusions were formulated:

(1) Laser heat treatment of Monel 400 leads to obtaining dendritic microstructure in which the grain size decreases with increasing the laser beam scanning velocity. Treated surfaces are free of cracks which means that there are no critical stresses in material during quick solidification if the process is carried out with applied parameters. Moreover, surfaces become more smooth if laser scanning speed is higher during the process. This effect results from lesser degree of mixing molten pool if exposure time of laser beam is shorter and was noted in previous research [8].

(2) Laser alloying of Monel 400 with initial boron layer results in obtaining microstructures of heterogeneous chemical composition composed of nickel borides, copperboron eutectic, and $\mathrm{Ni}-\mathrm{Cu}$ solid solution. Increasing the boron content leads to reducing the amount of dendrites in microstructure. This phenomenon was also spotted in the previous research [37]. Moreover, in layers alloyed with high boron content, dendrites are present between remelted areas and the substrate.
(3) Cracks were spotted on Monel 400 surfaces laser alloyed with boron. If the initial boron layer is $100 \mu \mathrm{m}$ thick, small amount of cracks occur on surfaces treated with $v_{1}=50 \mathrm{~m} / \mathrm{min}$ and $v_{1}=75 \mathrm{~m} / \mathrm{min}$. More cracks occur with increasing boron content. Spotted cracks are of different lengths and concentrations depending on laser beam scanning velocity. Small amount of long cracks occurs on surfaces treated with $v_{1}=5 \mathrm{~m} / \mathrm{min}$ and $v_{1}=25 \mathrm{~m} / \mathrm{min}$. High content of short cracks occurs on surfaces treated with higher scanning speeds. Cracks in areas laser alloyed with $200 \mu \mathrm{m}$ initial boron layer and $v_{1}=75 \mathrm{~m} / \mathrm{min}$ are so numerous that many of them are visible in cross-sections of obtained microstructure. This increase in number of cracks is associated with the presence of significant amount of boron in small re-melted zone which led to forming high concentration of nickel borides. These in turn, as ceramics, have low resistance against thermal shocks and are relatively brittle.

(4) In general, laser heat-treated areas become more shallow with increasing laser beam scanning velocity and, on the other hand, deeper with increasing the boron content. However, it was found that the area alloyed with initial boron layer $100 \mu \mathrm{m}$ thick and laser beam scanning velocity equal to $5 \mathrm{~m} / \mathrm{min}$ is more shallow than the laser heat-treated area of pure Monel 400. This phenomenon is considered to be the result of a decrease in heat conductivity due to low concentration of boron in relatively large molten pool.

(5) Microhardness of pure Monel 400 changes insignificantly as the result of laser heat treatment. On the other hand, an increase in microhardness was found due to laser alloying of Monel 400 with boron and the higher the boron content and laser beam scanning velocity are used for the process, the harder the alloyed area is. It results from obtaining higher concentration of nickel borides in smaller molten pool. Moreover, differences in microhardness distribution were spotted depending on laser beam scanning velocity. For low laser beam scanning velocity equal to $5 \mathrm{~m} / \mathrm{min}$, microhardness change is sharp between the coating and the substrate. This character of microhardness distribution was also reported in some papers on laser boriding $[8,14$, 16]. On the other hand, if higher laser beam scanning velocity is applied for the process, microhardness values decrease continuously with increasing the distance from the surface. This distribution is, in turn, similar to these obtained after diffusion boriding [9, 15].

Open Access This article is distributed under the terms of the Creative Commons Attribution 4.0 International License (http:// creativecommons.org/licenses/by/4.0/), which permits unrestricted use, distribution, and reproduction in any medium, provided you give appropriate credit to the original author(s) and the source, provide a link to the Creative Commons license, and indicate if changes were made. 
Publisher's Note Springer Nature remains neutral with regard to jurisdictional claims in published maps and institutional affiliations.

\section{References}

1. Special Metals Corporation (2000) High-performance alloys for resistance to aqueous corrosion, SMC-026. http://www.parrinst. com/wp-content/uploads/downloads/2011/07/Parr_InconelIncoloy-Monel-Nickel-Corrosion-Info.pdf. Accessed 30 July 2017

2. Dutta RS (2009) Corrosion aspects of Ni-Cr-Fe based and $\mathrm{Ni}-\mathrm{Cu}$ based steam generator tube materials. J Nucl Mater 393:343-349

3. Shoemaker LE, Smith GD (2006) A century of Monel metal: 19062006. JOM 58(9):22-26

4. Special Metals Corporation (2005) Monel alloy 400, SMC-053 http://www.specialmetals.com/assets/smc/documents/alloys/ monel/monel-alloy-400.pdf. Accessed 1 November 2017

5. Balandin YA (2006) Boron based complex wear-resistant coatings. Prot Met 42(2):137-139

6. Al-Azzawi AH, Sytchew J, Baumli P (2017) Increasing the surface hardness of cast iron by electrodeposition of borides in molten salts. Arch Metall Mater 62:1015-1018

7. Khenifer M, Allaoui O, Taouti MB (2017) Effect of boronizing on the oxidation resistance of $316 \mathrm{~L}$ stainless steel. Acta Phys Pol A 132(3):518-520

8. Bartkowska A, Bartkowski D, Swadźba R, Przestacki D, Miklaszewski A (2018) Microstructure, chemical composition, wear, and corrosion resistance of $\mathrm{FeB}-\mathrm{Fe}_{2} \mathrm{~B}-\mathrm{Fe}_{3} \mathrm{~B}$ surface layers produced on vanadis- 6 steel using $\mathrm{CO}_{2}$ laser. Int $\mathrm{J}$ Adv Manuf Technol 95:1763-1776

9. Sikorski K, Wierzchoń T, Bieliński P (1998) X-ray microanalysis and properties of multicomponent plasma-borided layers on steels. J Mater Sci 33(3):811-815

10. Taazim NT, Jauhari I, Miyashita Y, Sabri MFM (2016) Development and kinetics of $\mathrm{TiB}_{2}$ layers on the surface of titanium alloy by superplastic boronizing. Metall Mater Trans A 47(5): 2217-2222

11. Usta M, Ozbek I, Bindal C, Ucisik AH, Ingole S, Liang H (2006) A comparative study on borided pure niobium, tungsten and chromium. Vacuum 80(11-12):1321-1325

12. Mu D, Shen B-I, Yang C, Zhao X (2009) Microstructure analysis of boronized pure nickel using boronizing powders with $\mathrm{SiC}$ as diluent. Vacuum 83:1481-1484

13. Gunes I, Kayali Y (2014) Investigation of mechanical properties of borided nickel 201 alloy. Mater Des 53:577-580

14. Bartkowska A, Pertek A (2014) Laser production of B-Ni complex layers. Surf Coat Technol 248:23-29

15. Ueda N, Mizukoshi T, Demizu K, Sone T, Ikenaga A, Kawamoto M (2000) Boriding of nickel by the powder-pack method. Surf Coat Technol 126:25-30

16. Bartkowska A, Pertek A, Kulka M, Klimek L (2015) Laser surface modification of boronickelized medium carbon steel. Opt Laser Technol 74:145-157

17. Bartkowska A, Pertek A, Popławski M, Bartkowski D, Przestacki D, Miklaszewski A (2015) Effect of laser modification of B-Ni complex layer on wear resistance and microhardness. Opt Laser Technol 72:116-124

18. Bartkowska A, Pertek-Owsianna A, Popławski M, Bartkowski D (2015) Application of boron and copper to the laser modification of C45 steel surface. Mater Eng 5(207):276-280

19. Major B. (1996) Laser modification of steel by introducing carbides and borides. 3th Polish National Conference Surface Treatment. Conference materials: 263-269
20. Podchernyaeva A (1997) Formation and properties of a surface layer during comprehensive laser boriding of carbon steels. Powder Metall Met Ceram 36:67-70

21. Safonov AN (1998) Special features of boronizing iron and steel using a continuos-wave $\mathrm{CO}_{2}$ laser. Met Sci Heat Treat 40:6-10

22. Kinal G, Waligóra W (2005) Results of the test of laser boronizing of machine elements made of gray cast iron. Journal of Research and Applications in Agric Eng 2:54-58

23. Wiśniewski K, Pertek A (2009) Influence of laser alloying with amorphous boron on structure and microhardness of $41 \mathrm{Cr} 4$. Arch Metall Mater 54:111-114

24. Morimoto J, Ozaki T, Kubohori T, Morimoto S, Abe N, Tsukamoto M (2009) Some properties of boronized layers on steels with direct diode laser. Vacuum 83:185-189

25. Dutta MJ, Manna I (2003) Laser processing of materials. SadhanaAcad P Eng S 28:495-562

26. Devojno OG, Feldshtein E, Kardapolava MA, Lutsko NI (2018) On the formation features, microstructure and microhardness of single laser tracks formed by laser cladding of a $\mathrm{NiCrBSi}$ self-fluxing alloy. Opt Laser Eng 106:32-38

27. López López JM, Bakrania A, Coupland J, Marimuthu S (2016) Droplet assisted laser micromachining of hard ceramics. J Eur Ceram Soc 36(11):2689-2694

28. Liu H, Qin X, Huang S, Hu Z, Ni M (2018) Geometry modeling of single track cladding deposited by high power diode laser with rectangular beam spot. Opt Laser Eng 100:38-46

29. Wang F, Zhong L, Tang X, Xu C, Wan C (2018) A homogeneous focusing system for diode lasers and its applications in metal surface modification. Opt Laser Technol 102:197-206

30. Adak B, Nash P, Chen D, Swiglo A (2005) Microstructural characterization of laser cladding of $\mathrm{Cu}-30 \mathrm{Ni}$. J Mater Sci 40(8):2051-2054

31. Bhattacharya S, Dinda GP, Dasgupta AK, Mazumder J (2014) A comparative study of microstructure and mechanical behavior of $\mathrm{CO}_{2}$ and diode laser deposited $\mathrm{Cu}-38 \mathrm{Ni}$ alloy. J Mater Sci 49(6): 2415-2429

32. Nakata K, Tomoto K, Matsuda F (1996) Laser boronizing of copper alloy. T JWRI 25(1):37-41

33. Zhang C.-H., Wu C.-L., Zhang S., Jia Y.-F., Guan M., Tan J.-Z., Lin B. (2016) Laser cladding of $\mathrm{NiCrSiB}$ on Monel 400 to enhance cavitation, erosion and corrosion resistance. Rare Met 1-9

34. Przestacki D, Kukliński M, Bartkowska A (2017) Influence of laser heat treatment on microstructure and properties of surface layer of Waspaloy aimed for laser assisted machining. Int J Adv Manuf Tech 93(9-12):3111-3123

35. Przestacki D, Szymański D, Wojciechowski S (2016) Formation of surface layer in metal matrix composite A359/20SiCP during laser assisted turning. Compos A Appl S 91:370-379

36. Wojciechowski S, Przestacki D, Chwalczuk T (2017) The evaluation of surface integrity during machining of Inconel 718 with various laser assistance strategies. MATEC Web Conf 136:01006

37. Conde A., Zubiri F., de Damborenea y J. (2002) Cladding of Ni-CrB-Si coatings with a high power diode laser, Mat Sci Eng A-Struct 334(1-2): 233-238

38. Technical data for Copper. http://periodictable.com/Elements/029/ data.html. Accessed 5 April 2018

39. Technical data for Nickel. http://periodictable.com/Elements/028/ data.html. Accessed 5 April 2018

40. Technical data for Boron. http://periodictable.com/Elements/005/ data.html. Accessed 5 April 2018

41. Smolin MD, Grebenkina VG, Goryachev YM, Shvartsman EI (1984) Relationship between the thermal and electrical conductivities of nickel borides. Sov Powder Metall+ 23(6):477-479

42. Gordienko SP (2002) Thermodynamic characteristics of iron subgroup borides. Powder Metall Met C+ 41(3-4):169-172 